\section{A Modified Photoactivation Protocol Using Two Simultaneous Light-Curing Units for Bonding Brackets to Enamel}

Adauê Siegert de Oliveira, Rafael Correa Mirapalhete, Cássia Cardozo Amaral, Rafael Ratto de Moraes
Dental School, UFPel - Universidade

Federal de Pelotas, Pelotas, RS, Brazil

Correspondence: Prof. Rafael Moraes, Rua Gonçalves Chaves 457, sala 505, 96015-560, Pelotas, RS, Brasil. Tel: +55-53-3225-6741. ext.135. e-mail: moraesrr@gmail.com

\begin{abstract}
This study investigated the effect of a modified photoactivation protocol using two simultaneous light-curing units on the shear bond strength (SBS) of brackets to enamel. Metal brackets were bonded to bovine incisors using the resin-based orthodontic cement Transbond XT (3M Unitek). Four photoactivation protocols of the orthodontic cement were tested $(n=15)$ : Control: photoactivation for $10 \mathrm{~s}$ on each proximal face of the bracket at a time; Simultaneous: photoactivation for $10 \mathrm{~s}$ on both proximal faces of the bracket at the same time; One side-20s: photoactivation for $20 \mathrm{~s}$ at one proximal face of the bracket only; and One side-10s: photoactivation for $10 \mathrm{~s}$ only at one proximal face of the bracket. SBS was tested immediately or after 1000 thermal cycles. Adhesive remnant index (ARI) was classified. Data were subjected to two-way ANOVA and Student-NewmanKeuls' test $(\alpha=0.05)$. Pooled means \pm standard deviations for SBS to enamel (MPa) were:

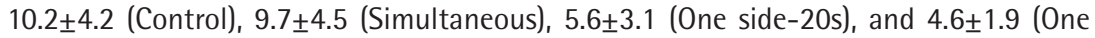
side-10s). Pooled SBS data for immediate and thermal cycled groups were $6.3 \pm 2.6$ and 8.8 \pm 5.2 . A predominance of ARI scores 1-2 and 0-1 was observed for the immediate and thermally cycled groups, respectively. In conclusion, simultaneous photoactivation of the orthodontic cement using two light-curing units, one positioned at each proximal face of the bracket, yielded similar bonding ability compared to the conventional light-curing method. Photoactivation of the orthodontic cement at one proximal face of the bracket only is not recommended, irrespective of the light-curing time used.
\end{abstract}

Key Words: aging, composite, Orthodontics, polymerization, shear bond strength.

\section{Introduction}

The development of adhesive materials has significantly facilitated the clinical practice in orthodontics $(1,2)$. The use of photoactivated resin-based agents in the bonding of orthodontic devices made the process more accurate, as the setting time of the cement can be controlled. Polymerization of the material used for bracket fixation depends on the access to curing light; however, orthodontic devices in general block the direct passage of the light electromagnetic spectrum. For this reason, multiple light exposures of the bracket-enamel interfaces are required to deliver a minimum radiant exposure (energy dose, $\mathrm{J} /$ $\mathrm{cm}^{2}$ ) for appropriate curing of the orthodontic cement (3).

Multiple light exposures increase the chair time of orthodontic dental treatments, which is inconvenient for the professional, uncomfortable for patients and, often, makes orthodontics unfeasible for children. In general, each orthodontic device applied needs between $20 \mathrm{~s}$ and $40 \mathrm{~s}$ of photoactivation for adequate polymerization $(4,5)$. The decrease of such time may cause a considerable reduction in the bond strength to enamel and consequent clinical problems, like premature debonding. The development of new photoactivation materials and/or protocols able to reduce the time to light exposure without interfering in the bond strength is therefore pertinent. This is particularly relevant considering that finding the optimal tooth position at which to place and bond a bracket is already time-consuming in the clinical practice (6).

Improvement in the polymerization promoting system of resin-based cements was recently indicated as an alternative to optimize the photoactivation protocols in orthodontics $(7,8)$. However, caution is necessary, as the exaggerated acceleration of the chemical reactions may increase the polymerization stress $(9,10)$ and interfere with the bonding to enamel. Another approach to accelerate the curing process is the change of light source. Highirradiance light-curing units (e.g.: plasma arc) have already been tested $(11,12)$, but they did not present a satisfactory response mainly because these units are not cost-effective and generally demand expensive maintenance.

Current curing units based on light-emitting diodes (LEDs) are less expensive and deliver higher irradiance than a few years ago. Thus, clinical approach of simultaneously using more than one LED unit for photoactivation procedures seems feasible in orthodontics. The rationale is to expose two sides of the bracket simultaneously to light, reducing in half the time spent with the photoactivation. Nonetheless, there is no clinical or laboratory evidence 
available concerning the effectiveness of such approach. There is always a risk for increased polymerization stress, thus investigation of that alternative curing method is mandatory before clinical application.

The aim of this study was to investigate the effect of using two simultaneous LED-based light-curing units during the photoactivation of orthodontic cement in the bond strength of brackets to enamel. Other curing methods were tested for comparison. This study tested two hypotheses: (i) the photoactivation protocol would have no negative impact on the bonding of brackets to enamel, and (ii) aging by thermal cycling would lead to decreased enamel bond strengths.

\section{Material and Methods}

\section{Experimental Design}

This in vitro study involved a complete randomized and blinded $4 \times 2$ factorial study design, in which the studied factors were: photoactivation protocol of the orthodontic cement (four levels: control, simultaneous photoactivation, and photoactivation in only one side of the bracket for $20 \mathrm{~s}$ or for $10 \mathrm{~s}$ ) and storage time of the specimens before the test (two levels: immediate testing or after aging by thermal cycling). The response variables were shear bond strength to enamel (MPa) and failure modes scored by the Adhesive Remnant Index (ARI) method (13). In each group, 15 specimens were tested.

\section{Bonding Procedures}

In total, 120 bovine permanent incisors recently extracted were used. The teeth had their roots embedded in PVC tubes for the crown buccal face to be in a perpendicular position to the horizontal level. After cleaning the surfaces with prophylactic paste and water, the buccal faces were dried and acid-etched using 37\% phosphoric acid for 15 $\mathrm{s}$, washed with air/water spray for $30 \mathrm{~s}$, and dried with compressed air.

Stainless steel Edgewise metallic brackets for upper central incisors, with a slightly curved base, were used (slot 0.022"; Morelli Ortodontia, Sorocaba, SP, Brazil). The brackets were fixed on the buccal faces using the photoactivated resin-based orthodontic cement Transbond XT (3M Unitek, Monrovia, CA, USA). The primer was not used for the simplicity of the bonding protocol and because it has been shown that the use of the primer might not interfere with the bond strength of brackets to enamel in vitro (14). For all groups, after acid etching, the orthodontic cement was applied to the bracket base and the bracket was hand-pressed to the center of the buccal face using direct bond bracket tweezers. Excess cement was removed from all bracket-enamel margins with a dental explorer. Four different photoactivation protocols were tested (30 specimens per group):

Control: the orthodontic cement was photoactivated for $20 \mathrm{~s}, 10 \mathrm{~s}$ on each proximal face of the bracket (right and left sides), using a LED curing unit (Radii Cal; SDI, Bayswater, Victoria, Australia) with irradiance of $1400 \mathrm{~mW} /$ $\mathrm{cm}^{2}$. This photoactivation protocol is recommended by the manufacturer of the orthodontic cement;

Simultaneous: the orthodontic cement was photoactivated for $10 \mathrm{~s}$ on each proximal face of the bracket (right and left sides) simultaneously using two similar light-curing units with similar irradiance levels, which were regularly checked with a calibrated power meter (Ophir Optronics, Danvers, MA, USA);

One side-20s: the orthodontic cement was photoactivated for $20 \mathrm{~s}$ on a single proximal face of the bracket (right side);

One side-10s: the orthodontic cement was photoactivated for $10 \mathrm{~s}$ on a single proximal face of the bracket (right side). This protocol was tested because the manufacturer of the orthodontic cement indicates that, depending on the light-curing unit used, photoactivation times as short as $10 \mathrm{~s}$ ( $5 \mathrm{~s}$ on each proximal side of the bracket) could be used.

\section{Bond Strength Test and Failure Analysis}

The same operator carried out all bonding procedures. After bonding, 15 specimens from each photoactivation method group were immediately tested while the other 15 specimens were tested after aging with 1000 thermal cycles. Thermal cycling involved alternated immersion in water at $5 \pm 5^{\circ} \mathrm{C}$ and $55 \pm 5^{\circ} \mathrm{C}$ using a $30 \mathrm{~s}$ dwell time (model 521-4D; Nova Ética Ind. Ltda., Vargem Grande, SP, Brazil). The specimens were stored in distilled water at $37^{\circ} \mathrm{C}$ for up to $10 \mathrm{~min}$ before immediate testing or aging. For the shear bond strength test, a mechanical testing machine was used (DL500; EMIC, São José dos Pinhais, PR, Brazil). A knife-edged chisel was placed at the tooth-bracket interface and a compressive load was applied at a $0.5 \mathrm{~mm} /$ min crosshead speed until failure of the bonding. Bond strength values were calculated in $\mathrm{MPa}$ considering the bracket base area. After the test, the teeth surfaces were observed in a stereomicroscope, at $\times 40$ magnification, for classification of the ARI scores (13): Score 0: no amount of adhesive attached to enamel; Score 1: less than half of adhesive attached to enamel; Score 2: more than half of adhesive attached to enamel; Score 3 : all adhesive attached to enamel.

\section{Statistical Analysis}

Enamel bond strength data were transformed to ranks and submitted to a two-way Analysis of Variance (photoactivation protocol $\times$ storage time). All pairwise 
multiple comparison procedures were carried out using the Student-Newman-Keuls' method. ARI data were analyzed by Kruskal-Wallis test separately for each storage time, while ARI individual comparisons between the storage times within each photoactivation protocol were carried out using the Wilcoxon test. The analyses were carried out using the SigmaStat 3.5 software (Systat Software Inc., San Jose, CA, USA). The significance level $\alpha=0.05$ was set for all analyses.

\section{Results}

The results of shear bond strength test are presented in Table 1. The factors 'photoactivation protocol' $(p<0.001)$ and 'storage time' $(p=0.003)$ were significant, while the interaction between the factors was not significant

Table 1. Means (standard deviations) of shear bond strength to enamel, MPa $(n=15)$

\begin{tabular}{lccc}
\hline \multirow{2}{*}{$\begin{array}{l}\text { Photoactivation } \\
\text { protocol }\end{array}$} & \multicolumn{2}{c}{ Storage time } & Pooled \\
\cline { 2 - 3 } & $\begin{array}{c}\text { Immediate } \\
\text { data* min })\end{array}$ & $\begin{array}{c}\text { Thermally cycled } \\
\text { (1000 cycles })\end{array}$ & \\
\hline Control & $7.9(2.1)$ & $12.5(4.5)$ & $10.2(4.2) \mathrm{a}$ \\
Simultaneous & $8.3(1.9)$ & $11.2(5.9)$ & $9.7(4.5) \mathrm{a}$ \\
One side-20s & $4.9(2.2)$ & $6.4(3.7)$ & $5.6(3.1) \mathrm{b}$ \\
One side-10s & $4.2(1.5)$ & $5.1(2.2)$ & $4.6(1.9) \mathrm{b}$ \\
Pooled data* & $6.3(2.6) \mathrm{B}$ & $8.8(5.2) \mathrm{A}$ & \\
\hline
\end{tabular}

*Data are presented as pooled means because the interaction between the two factors was not significant $(p=0.694)$. Different uppercase letters in the same row indicate significant differences between the storage times; different lowercase letters in the same column indicate significant differences between the photoactivation protocols $(\mathrm{p}<0.05)$ $(p=0.694)$. Thus, data in Table 1 are presented as pooled means for each factor. The Control and Simultaneous methods were similar to each other, both generating enamel shear bond strength significantly higher than the other methods.

Results of the ARI analysis are shown in Figure 1. No statistically significant differences were observed among the photoactivation protocols in the storage times immediate $(p=0.589)$ and thermally cycled $(p=0.481)$. In the individual comparisons for each photoactivation protocol (immediate $x$ thermally cycled), no significant differences were detected for the groups Control $(p=0.173)$, One side-20s $(p=0.946)$, and One side-10s $(p=0.240)$. For the Simultaneous group, there was a significant difference between the storage times $(p=0.027)$, with predominance $(80 \%)$ of $A R I$ scores 2 and 3 in the immediate time and predominance of scores 0 and 1 (60\%) after thermal cycling.

\section{Discussion}

Results of the bond strength of the Control and Simultaneous groups were similar. The higher bond strength observed for the protocols that involved photoactivation in both proximal faces of the bracket (individual or simultaneous) is explained by a higher exposure of the orthodontic cement to light during these photoactivation methods. The brackets interfere with the irradiance (light intensity) and quality of the light reaching the cement, which is interposed between the bracket and tooth, even when ceramic brackets are used (15). Thus, when using two light exposures on both proximal bracket faces, a larger cement area is reached by photons, resulting in higher degree of $\mathrm{C}=\mathrm{C}$ conversion. As the bonding between bracket and enamel depends on appropriate polymerization

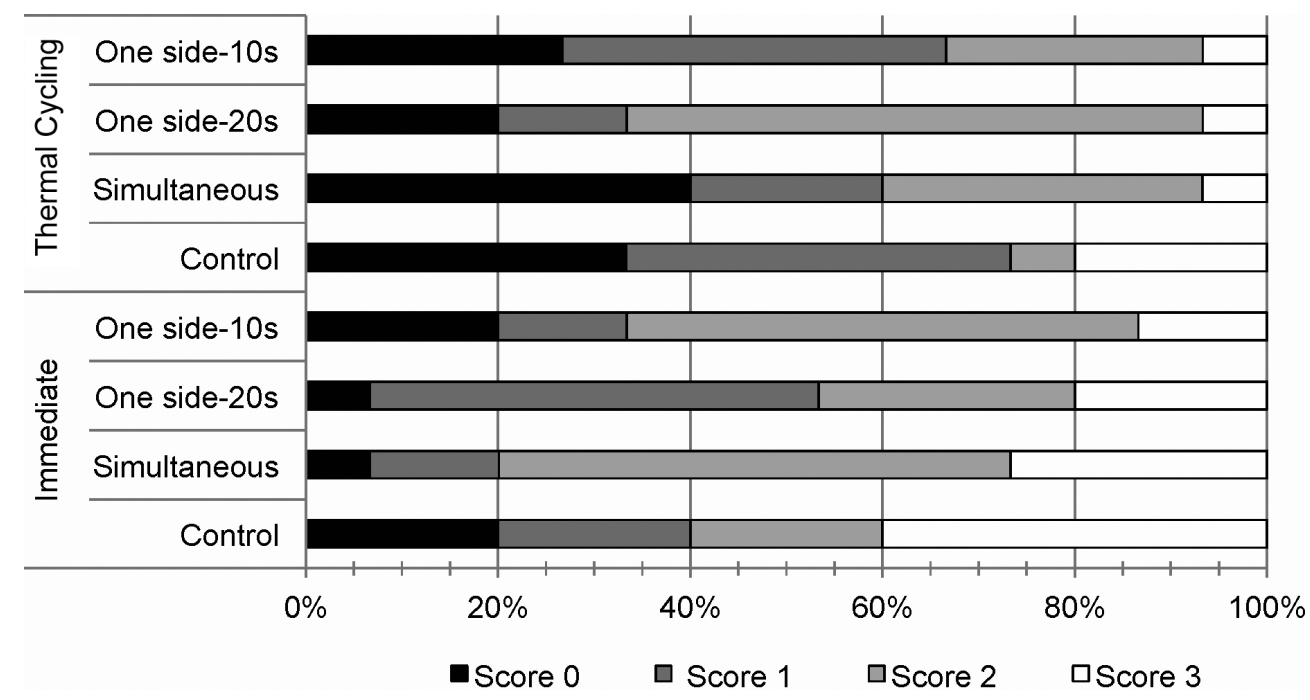

Figure 1. Frequency of ARI scores (\%) for all groups. For the Simultaneous group, there was a significant difference between the storage periods. No other significant differences were observed in failure modes across groups. 
of the orthodontic cement, it seems that appropriate polymerization is not obtained when the light is shined from one bracket proximal face only, regardless of using 10 or 20 s light-curing. Thus, the first tested hypothesis is rejected. This is explained by the fact that the degree of $\mathrm{C}=\mathrm{C}$ conversion of a polymer may have a direct effect on its bond ability to dental substrates (16).

Results of the present study provided evidence that the method using two individual light-curing units placed simultaneously at both proximal faces of the bracket was effective for bonding brackets to enamel. This finding is interesting because it could allow reducing approximately $50 \%$ of the clinical time needed for photoactivation of orthodontic cements. A possible risk associated to the use of this protocol would be generating higher polymerization stress at the adhesive interface, as activation at both proximal faces could lead to a "competition" between shrinkage stresses from each side of the bracket (17). A possible increase in polymerization shrinkage could result in the formation of areas with more fragile bonded interfaces. Although it might not be ruled out that this mechanism has occurred in the material microstructure and in the$$
\text { strength to enamel was significantly improved after }
$$
thermal cycling, thus the second tested hypothesis is also rejected. In general, thermal cycling has a deleterious effect on the bonding of brackets to enamel (18), which is usually attributed to the degradation of the polymer during aging and, mainly, the stress caused at the bonded interface due to the constant temperature changes. The thermal variations tend to cause stress because the different materials from the bonded interface have different thermal expansion coefficients. As a result, the materials react differently to cold (shrinkage) and heat (expansion) during cycling, resulting in stress at the interface. On one hand, one might link the result after thermal cycling to the number of cycles used, which was probably not sufficient to generate significant stress at the bonded interfaces. However, previous studies have also reported that the bond strength of brackets to enamel might not be affected by thermal cycling (19-22).

On the other hand, a potential explanation for the higher bond strength after thermal cycling is that the cements had a higher $\mathrm{C}=\mathrm{C}$ conversion during aging as compared to the immediate groups. The immediate groups were tested $10 \mathrm{~min}$ after bonding the brackets in order to simulate the time span in the clinical setup between fixing the last brackets to tooth surfaces and positioning the orthodontic archwire. However, the degree of $\mathrm{C}=\mathrm{C}$ conversion of polymeric composites tends to increase in the first 24 to $48 \mathrm{~h}$ after photoactivation, mainly in the presence of heat, even in mild temperatures as those in the oral cavity (23). This "late" polymerization may explain the higher bond strength after aging. Proper polymer formation and crosslinking play key roles in the bonding between orthodontic cement, bracket mesh, and dental surface. The ARI results for the Simultaneous group may also be explained by the higher polymeric conversion after thermal cycling. Higher $\mathrm{C}=\mathrm{C}$ conversion leads to a better interlocking of the cement with the bracket mesh; this could make the cement to be mechanically retained to the orthodontic device after the shear test, leaving no or little cement remnants at the tooth surface.

In conclusion, the findings of the present study have clinical applicability. The use of the simultaneous photoactivation protocol tested here could reduce the chair time for bonding brackets. Having in mind that the modified protocol did not interfere with the bond strength to enamel, it seems reasonable to indicate that the use of two light-curing units simultaneously to photoactivate the orthodontic cement could be applied clinically. In contrast, simplification of adhesive procedures by using a single light exposure at only one proximal face of the bracket is not recommended as it might reduce the bonding ability of the brackets to enamel.

\section{Resumo}

Este estudo investigou o efeito de um protocolo modificado de fotoativação utilizando duas unidades de fotopolimerização simultâneas na resistência de união ao cisalhamento (RUC) de braquetes ao esmalte. Braquetes metálicos foram fixados a incisivos bovinos utilizando o cimento ortodôntico resinoso Transbond XT (3M Unitek). Quatro protocolos de fotoativação do cimento ortodôntico foram testados $(n=15)$ : Controle: fotoativação por $10 \mathrm{~s} \mathrm{em}$ cada face proximal do braquete de cada vez; Simultâneo: fotoativação por $10 \mathrm{sem}$ ambas as faces proximais do braquete ao mesmo tempo; Um lado-20s: fotoativação por $20 \mathrm{~s}$ em uma face proximal do braquete apenas; e Um lado-10s: fotoativação por 10 s apenas em uma face proximal do braquete. A RUC foi testada imediatamente ou após 1000 ciclos térmicos. 0 Índice de Remanescente de Adesivo (IRA) foi classificado. Os dados foram submetidos a ANOVA de duas vias e teste de Student-Newman-Keuls $(\alpha=0,05)$. As médias agrupadas \pm desvios-padrão de RUC ao esmalte (MPa) foram: 10,2 $\pm 4,2$ (Controle), 9,7 $\pm 4,5$ (Simultâneo), $5,6 \pm 3,1$ (Um lado-20s), e 4,6 $\pm 1,9$ (Um lado-10s). Os dados agrupados de RUC para os grupos imediatos e termociclados foram $6,3 \pm 2,6$ e $8,8 \pm 5,2$. Predominância de escores IRA 1-2 e 0-1 foi observada para os grupos imediatos e termociclados, respectivamente. Em conclusão, a fotoativação simultânea do cimento ortodôntico utilizando duas fontes de luz, uma posicionada em cada face proximal do braquete, gerou similar capacidade de união ao método convencional de fotopolimerização. Fotoativação do cimento ortodôntico em apenas uma face proximal do braquete não é recomendada, independente do tempo de fotoativação utilizado.

\section{References}

1. Read MJ. The bonding of orthodontic attachments using a visible light cured adhesive. Br J Orthod 1984:20:11-16.

2. Mandall NA, Millett DT, Mattick CR, Hickman J, Worthington HV, Macfarlane TV. Orthodontic adhesives: a systematic review. J Orthod 
2002:29:205-210.

3. Halvorson RH, Erickson RL, Davidson CL. Energy dependent polymerization of resin-based composite. Dent Mater 2002:18:463469.

4. Oesterle $\sqcup$, Messersmith ML, Devine SM, Ness CF. Light and setting times of visible-light-cured orthodontic adhesives. J Clin Orthod 1995:6:29-31.

5. Staudt CB, Krejci I, Mavropoulos A. Bracket bond strength dependence on light power density. J Dent 2006:34:498-502.

6. Oliveira AS, Barwaldt CK, Bublitz LS, Moraes RR. Impact of bracket displacement or rotation during bonding and time of removal of excess adhesive on the bracket-enamel bond strength. J Orthod 2014:41:124127.

7. Costa $A R$, Vedovello-Filho $M$, Correr, $A B$, Vedovello SA, Puppin-Rontani RM, Ogliari FA, et al.. Bonding orthodontics brackets to enamel using experimental composites with an iodonium salt. Eur J Orthod 2014:36:297-302.

8. Soares $E F$, Costa $A R$, Correr $A B$, Vedovello $S A$, Vedovello Filho $M$, Ogliari FA, et al.. Effect of composite containing an iodonium salt on the bond strength of brackets to bovine enamel. Braz Dent J 2014:25:237-240.

9. Gonçalves LS, Moraes RR, Ogliari FA, Boaro L, Braga RR, Consani S. Improved polymerization efficiency of methacrylate-based cements containing an iodonium salt. Dent Mater 2013:29:1251-1255.

10. Lopes MB, Santos AM, Coelho D, Junior AG, Ogliari FA, Moraes RR. Influence of diphenyliodonium hexafluorophosphate on the bond strength and mechanical properties of model resin cements. Int J Adhes Adhes 2013:47:125-128.

11. James JW, Miller BH, English JD, Tadlock LP, Buschang PH. Effects of high-speed curing devices on shear bond strength and microleakage of orthodontic brackets. Am J Orthod Dentofacial Orthop 2003:123:555561.

12. Gonçalves PR, Moraes RR, Costa AR, Correr AB, Nouer PR, Sinhoreti MA, et al.. Effect of etching time and light source on the bond strength of metallic brackets to ceramic. Braz Dent J 2011:22:245-248.

13. Artun J, Bergland S. Clinical trials with crystal growth conditioning as an alternative to acid-etch enamel pretreatment. Am J Orthod
Dentofacial Orthop 1984:85:333-340.

14. Neves AM, Romano FL, Correr AB. Shear bond strength of composites Concise and Transbond XT with and without bonding agent. Dental Press J Orthod 2011:16:63-68.

15. Eliades $T$, Johnston WM, Eliades G. Direct light transmittance through ceramic brackets. Am J Orthod Dentofacial Orthop 1995:107:11-19.

16. $\mathrm{Xu} \mathrm{X}$, Sandras DA, Burgess JO. Shear bond strength with increasing light-guide distance from dentin. J Esthet Restor Dent 2006:18:19-27.

17. Davidson $\mathrm{CL}$, De Gee AJ, Feilzer A. The competition between the composite-dentin bond strength and the polymerization contraction stress. J Dent Res 1984:63:1396-1399.

18. Gale MS, Darvell BW. Thermal cycling procedures for laboratory testing of dental restorations. J Dent 1999;27:89-99.

19. Kitayama S, Nikaido T, Ikeda M, Foxton RM, Tagami J. Enamel bonding of self-etch and phosphoric acid-etch orthodontic adhesive systems. Dent Mater J 2007;26:135-143.

20. Amm EW, Hardan LS, BouSerhal JP, Glasl B, Ludwig B. Shear bond strength of orthodontic brackets bonded with self-etching primer to intact and pre-conditioned human enamel. J Orofac Orthop 2008:69:383-392.

21. Namura Y, Tsuruoka T, Ryu C, Kaketani M, Shimizu N. Usefulness of orthodontic adhesive-containing fluorescent dye. Eur J Orthod 2010:32:620-626.

22. Costa AR, Correr AB, Puppin-Rontani RM, Vedovello SA, Valdrighi HC,

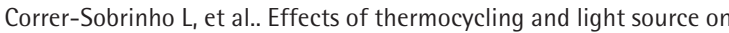
the bond strength of metallic brackets to bovine teeth. Braz Dent J 2011:22:486-489.

23. Watts DC, Mcnaughton V, Grant AA. The development of surface hardness in visible light-cured posterior composites. J Dent 1986;14:169-174.

Received January 19, 2015 Accepted June 24, 2015 